Canadian

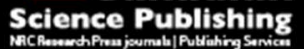

Canadian Journal of Civil Engineering Revue canadienne de génie civil

Finite Element Model Calibration of Multi-Story Buildings through Interferometric Imaging and Spectral Ratio Method

\begin{tabular}{|r|l|}
\hline Journal: & Canadian Journal of Civil Engineering \\
\hline Manuscript ID & cjce-2015-0467.R1 \\
\hline Manuscript Type: & Article \\
\hline Date Submitted by the Author: & $17-J a n-2016$ \\
\hline Complete List of Authors: & KAYA, YAVUZ; The University of British Columbia \\
\hline Keyword: & $\begin{array}{l}\text { Finite Element Model Calibration, Interferometric Imaging, Spectral Ratio of } \\
\text { a story }\end{array}$ \\
\hline \multicolumn{2}{|l}{} \\
\hline
\end{tabular}

SCHOLARONE ${ }^{m}$

Manuscripts 


\title{
Finite element model calibration of multi-story buildings through Interferometric Imaging and Spectral Ratio method
}

\author{
Yavuz Kaya
}

\begin{abstract}
In order to identify and calibrate the Finite Element (FE) model for multi-story buildings, a simplified approach is being introduced in this paper; this methodology is based on Interferometric Imaging and encompasses Spectral Ratio (SR) method. The Interferometric Imaging provides a new set of seismic data free of coupling between structure to its subsurface and independent of the excitation of the building. The SR method, on the other hand, is the ratio of Fourier Amplitude Spectra of the roofdeconvoulted records on two adjacent stories. The newly introduced methodology enables each story to be identified uniquely for its stiffness since the SR of a particular story is dependent only on the properties of itself and the stories above.
\end{abstract}

Keywords Finite Element Model Calibration, Interferometric Imaging, Spectral Ratio of a story

\footnotetext{
${ }^{1}$ Research Associate, Department of Civil Engineering, The University of British Columbia, Vancouver, Canada, 6250 Applied Science Lane, V6T 1Z4, Canada, Phone: (604) 822-9842, E-mail: kayaya@mail.ubc.ca
} 


\section{Introduction}

In order to develop effective, reliable tools and techniques to maintain the safety and integrity of multi-story buildings, scientists and engineers have conducted substantial research in vibration-based damage identification. A broader range of these tools and techniques have been developed over the last three decades to identify damage on different types of structures (Fan and Qiao 2011; Chang et al. 2003; Doebling et al. 1996). The prevailing way to detect structural change on structure, for instance damage, is to use vibration-based techniques; these techniques conclude that damage-induced changes in the physical properties of structure, such as mass, stiffness, and damping might cause detectable changes in modal properties of structure (natural frequencies, modal damping ratio, and mode shapes) (Fan and Qiao 2011). Some of these damage identification methods make use of the Finite Element (FE) model of structure (Kim and Stubbs 2003; Hadjileontiadis and Douka 2007; Pandey et al. 1991; Ratcliffe 1997; Stubbs et al. 1995). These vibration-based methods assume that the detailed FE model of the structure under study is available for damage identification; and thus the FE model is calibrated based on the vibration-based model identification. The mass and the stiffness of structural elements in the FE model is optimized or updated by ensuring that the updated FE model can better reflect the measured or recorded data than the initial FE model. The current practice of calibrating the FE model of a building involves methods that linearly matches the modal properties of the building using optimizations (Jaishi and Ren 2005), genetic algorithm (Levin and Lieven 1998), Kalman Filters (Naets et al. 2015a; Naets et al. 2015b; Eftekhar et al. 2015; Bernal and Ussia 2015), etc. 
This paper introduces a new simplified methodology to detect structural changes (e.g., damage) on multi-story buildings by calibrating the FE model of the structure. The new methodology is based on the Interferometric Imaging and the Spectral Ratio (SR) of each story. The Interferometric Imaging utilizes the correlations among synchronized seismic records collected from different locations and provides new set of seismic data that are free of the coupling of structure to its subsurface and independent of the excitation of the building (Snieder and Safak 2006). The SR of each story is defined as the ratio of the Fourier Amplitude Spectra of the roof-deconvoluted records on two adjacent floors, thus enabling the stiffness of each story to be identified uniquely. The methodology requires that the synchronized measurements are available for each story. However, multi-story buildings are usually instrumented at a limited number of floors, and the structural response (e.g., acceleration, velocity, or displacement) at non-instrumented floors remains unknown. In such cases, new methodologies is proposed to estimate the structural response at non-instrumented floors using the acceleration data recorded at instrumented floors (Kaya et al. 2015; Kaya and Dowling 2016).

\section{Calibration of Finite Element model}

\subsection{Interferometric Imaging and Spectral Ratio method}

The recorded total accelerations on multi-story buildings involve the coupling of the building to its subsurface and are not independent of the excitation of the building (Snieder and Safak 2006). Total accelerations are formed by the combination of both upgoing, down-going waves as well as their refractions and reflections on each story (Safak 1999). Furthermore, it is usually assumed that the building is perfectly fixed at foundation level. The wave velocity of a shear-beam building from broader band records 
(roof-deconvolved) are less affected by the Soil Structure Interaction (SSI) because it is biased towards the values representative of higher frequencies, which are less effected by SSI; however, the wave propagation of the building on a flexible soil is still dispersive when foundation rocking is present (Rahmani et. al. 2015). Such effects can be removed from the recorded total acceleration using the Interferometric Imaging method.

Interferometry utilizes the correlations among the synchronized records collected from different locations, and provides a new approach to analyze seismic data from instrumented structures (Safak 1995). These correlations can be shown to lead to the Green's functions that account for the wave propagation between different receivers in the structure (Lobkis and Weaver 2001; Derode et. al. 2003; Wapenaar et al. 2004; Snieder 2004). The properties of the waves can be investigated without knowing the seismic input that generated the waves. The travel times of the waves, and their reflections and transmissions on various stories of the building provide a critical insight into the characteristics of the structure (Safak 1999).

Based on the concept of interferometric imaging, it is showed that when de-convolved by the roof record (an acceleration that is recorded at the roof level of the multi-story building), the floor accelerations in a multi story building becomes a sum of one attenuating up-going and down-going wave along with the height of the building (Snieder and Safak 2006) as can be seen in (1b). and in Fig.2 for the Factor building in Los Angeles, USA. The detailed analytical proof for this is given in (Snieder and Safak 2006), and the de-convolution in frequency domain is defined as 


$$
\begin{gathered}
T_{n}(z, \omega)=\frac{u_{n}(z, \omega) \cdot u_{N}^{*}(z=H, \omega)}{\left|u_{N}(z=H, \omega)\right|+\varepsilon} \\
T_{n}(z, \omega)=\frac{1}{2}\left(e^{i k(z-H)} \cdot e^{-\gamma|k|(z-H)}+e^{i k(H-z)} \cdot e^{-\gamma|k|(H-z)}\right)
\end{gathered}
$$

where $u_{n}(z, \omega)$ and $u_{N}(z=H, \omega)$ are the signals recorded at height $z$ and $H$ of the building, respectively (Fig.1); the superscript $(*)$ denotes the complex conjugate; $H$ is the total height of the building; $\omega$ is the circular frequency; $\varepsilon$ is the stabilization parameter and can be taken as $10 \%$ of the average spectral power of $u_{N}(\omega)$ if not known; $k=\omega / c$ is the wavenumber; $c$ is the wave propagation velocity of a uniform shear beam (Iwan $1977) ; T_{n}(z, \omega)$ is the deconvolution of $u_{n}(z, \omega)$ out of $u_{N}(z=H, \omega)$ at height $z$ (the $n^{\text {th }}$ floor).

Fig. 2 shows a two-second segment of the floor accelerations after being de-convolved by the roof accelerations. The horizontal axes denote the time and the floor levels while the vertical axis displays the amplitude of accelerations that are de-convolved by the recorded roof acceleration. The de-convolved accelerations are color-coded based on their amplitudes. As clearly seen in the Fig.2, when de-convolved by the roof acceleration, the accelerations on each story of the building becomes a superposition of one simple up-going \& one down-going wave along the height of the building. Furthermore, as the roof-deconvolved records do not show any sign of reflation along the height of the building, which are free of the coupling of the building to its subsurface and independent of the excitation of the building (Snieder and Safak 2006). If there was a reflection at any floor level, the up-going or the down-going propagating wave would 
have changed its propagation direction; for example, for an up-going wave, it would have reflected from one floor level, and some portion of the wave would have travelled downwards, but this is clearly not the case in Fig.2 because the up-going wave reflects from the top floor only.

The key implication of these observations is that any structural change, for instance damage, in a story of the building will only change the roof-deconvolved records at the stories below that story; assuming that only the down-going wave parts of the roofdeconvolved records are used, as indicated by positive times shown on Fig.2. Therefore, we can then take the ratio of Fourier Amplitude Spectra of the roof-deconvolved records at two adjacent floor levels to calculate the Spectral Ratio, $S R_{n}(\omega)$ for $\mathrm{n}^{\text {th }}$ story as seen in (2).

$$
S R_{n}(\omega)=\frac{T_{n}\left(z_{t}, \omega\right)}{T_{n}\left(z_{b}, \omega\right)}
$$

where $T_{n}\left(z_{t}, \omega\right)$ and $T_{n}\left(z_{b}, \omega\right)$ are the Fourier amplitude spectra of the roofdeconvolved accelerations, using only the down-going wave, calculated at the top and bottom of the $n^{\text {th }}$ story, respectively; $S R_{n}(\omega)$ is the spectral ratio of $n^{\text {th }}$ story. Using the Transfer Matrix method, it has been proofed that the roof-deconvolved record at any floor will only depend on the physical properties of the stories above that floor (Kaya et al. 2015) as seen in Eq. (3a) and (3b) for the top story and the story below the top story, respectively.

$$
S R_{n}(\omega)=\frac{\omega_{n}^{2}}{\omega_{n}^{2}-\omega^{2}}
$$




$$
S R_{n-1}(\omega)=\frac{\omega_{n-1}^{2}\left(m_{n-1} / m_{n}\right)\left(\omega^{2}-\omega_{n}^{2}\right)}{\omega^{2} \omega_{n}^{2}+\left(m_{n-1} / m_{n}\right)\left(\omega^{2}-\omega_{n}^{2}\right)\left(\omega_{n-1}^{2}-\omega^{2}\right)}
$$

where $m_{n}$ is the mass of the $\mathrm{n}^{\text {th }}$ story and $\omega_{n}$ is the fixed-based frequency of the $\mathrm{n}^{\text {th }}$ story. The Spectral Ratio concept was first introduced by Kaya et al. 2015 using Transfer Matrix formulation, which defines the relationship between the force and the displacement of any adjacent stations of a structure (Holzer 1921 and Thomas 2003). It is shown that the $S R_{n}(\omega)$ is a function of the physical properties of the story $n$ and the stories above it, for instance it does not depend on the physical properties of the stories below (Kaya et al. 2015). By studying the transfer function of a simple 2-DOF model, for small damping ratios (e.g., $\xi_{n}<0.20$ ), it is shown that the spectral ratio of the transfer function of the upper-floor acceleration to that of the lower-floor acceleration in a story always peaks at or near the predominant frequency of the fixed-based frequency (i.e., $\omega_{n}^{2}=k_{n} / m_{n}$ ) of that story (i.e., as if that story were a fixed-based one-story building) (Safak 1995).

The spectral ratio of the roof-deconvolved accelerations for the top two floors, $\operatorname{SR}_{N}(\omega)$ is a function of the individual frequency $\omega_{N}$ of the top story (i.e. $\omega_{N}^{2}=k_{N} / m_{N}$ ) and has its peak at $\omega=\omega_{N}$. The spectral ratio is not influenced by the dynamic characteristics of the stories below, neither by the excitation. Thus, by taking the spectral ratio of $N^{\text {th }}$ story, the natural frequency of the top story and consequently the stiffness of the top story can be determined uniquely assuming that the mass of the top floor is known or estimated.

The ratio of $S R_{n}(\omega)$, for instance, is a function of the properties of stories of $n^{\text {th }}$ and stories above it (i.e., $(n+1)^{\text {th }},(n+2)^{\text {th }}$, up to the $N^{\text {th }}$ story); this ratio does not depend on 
the properties of the stories below ( $3 \mathrm{a}$ and $3 \mathrm{~b}$ ). Since $\omega_{n+1}$ and $k_{n+1}$ has already been determined earlier from the spectral ratio of $S R_{n+1}(w)$, now the $\omega_{n}$ and the $k_{n}$ can be determined from the spectral ratio of $S R_{n}(\omega)$. It is assumed that the mass of $m_{n}$ is known or estimated. Determination of $\omega_{n}$ and $k_{n}$ does not validate the $\omega_{n+1}$ and $k_{n+1}$, which are already determined in the pervious step, because these properties belong to one story above and are not affected by the physical properties of the stories below. Consequently, using the SR of each story, the FE model of the building can be calibrated by matching the predominant frequency of the SRs provided that we start from the top story. More detail on this procedure can be found in Kaya et al. 2015.

\subsection{Numerical example for Spectral Ratio method}

To illustrate the SR concept, we used the simulated response of a 10-story building modeled as an elastic, viscously damped shear-beam with piecewise uniform material properties. The building is supported by a half-space and excited by $\mathrm{M}_{\mathrm{w}}=7.3$ Kocaeli earthquake (Erdik 2001), which is assumed to be incident plane shear waves propagating vertically. It is assumed that the building is instrumented on each story of the building, and $10 \%$ of noise is included in the simulated data. The stiffness and the mass of each story are $0.5 \mathrm{e}-2 \mathrm{kN} / \mathrm{m}$ and $5.625 \mathrm{e}-6$ ton, respectively, and $4 \%$ damping is assumed for all modes. Damage is simulated at the $6^{\text {th }}$ and $9^{\text {th }}$ stories of the building by reducing the stiffness of these stories by $20 \%$. Table 1 lists the modal frequencies for the damaged and undamaged structures. Note that the $20 \%$ decrease in the $6^{\text {th }}$ and the $9^{\text {th }}$ story stiffness results in only $3.3 \%$ change in the modal frequencies of the building. Calculated spectral ratios for each story are depicted in Fig.3, 4 and 5 for the damaged and the undamaged structures. 
As Fig. 3 illustrates, because some of the damage is simulated at the $9^{\text {th }}$ story level, the spectral ratios both for the damaged and the undamaged structure at the $10^{\text {th }}$ story exhibit the same SR amplitude of 14.86 and the first predominant frequency, no frequency shift, of $4.79 \mathrm{~Hz}$. However, the first predominant frequency of the $9^{\text {th }}$ story's spectral ratio of the damaged structure is shifted by $13 \%$ from $2.93 \mathrm{~Hz}$ to $2.57 \mathrm{~Hz}$. Moreover, all of the stories below $9^{\text {th }}$ story experience similar frequency shifts. The frequency shift at the $9^{\text {th }}$ story indicates a structural change, for instance damage, on the building because it is the highest story at which such frequency shift exists; however, the frequency shifts at the stories below the $9^{\text {th }}$ story do not necessarily indicate a structural change because such sifts may also stem from the structural changes that may exist on upper stories, i.e., spectral ratio of a story will be effected by the damage either at that story or stories above it.

The FE model of the undamaged building, therefore, is calibrated only on the $9^{\text {th }}$ story (Damaged (1) state in Table 2) by matching the first predominant frequency of the $9^{\text {th }}$ story spectral ratio (i.e., reducing the $9^{\text {th }}$ story stiffness by $20 \%$ ), and the Fig.4 shows the spectral ratios of each story after the FE model of the building is calibrated at the $9^{\text {th }}$ story. In this case, the SR at the $6^{\text {th }}$ story is shifted by $5 \%$ from $1.34 \mathrm{~Hz}$ to $1.27 \mathrm{~Hz}$, but the SR of the $7^{\text {th }}$ and the $8^{\text {th }}$ stories do not experience any frequency shifts because the FE model of the building is already calibrated at the $9^{\text {th }}$ story level, thus no structural change is observed on $7^{\text {th }}$ and $8^{\text {th }}$ stories. The stories below $6^{\text {th }}$ experience similar frequency shifts in their SRs; therefore, the FE model of the structure is again calibrated only on $6^{\text {th }}$ story (Damaged (2) state in Table 2) by matching the first predominant frequency of the 
SR of this story, i.e. $6^{\text {th }}$ story stiffness is reduced by $20 \%$. Finally, Fig. 5 shows the SRs for the undamaged building as well as the structure whose FE model is calibrated. No frequency shift is observed in any of the SRs; thus indicating that no further calibration on the FE model is required concluding that the FE model of the building is fully calibrated on all stories of the building. The calibrated FE model can be used to detect the location and the extent of the damage to the building by comparing its calibrated FE model to its initial one. Table 2 compares the Undamaged and the Damaged (2) states of the structure, further proving the validity of this type of modeling.

\section{Conclusion}

A simple approach is introduced to identify and calibrate analytical models of multi-story buildings from their vibration records. The discussed method is based on the Interferometric Imaging and requires that vibration time histories are known on every floor level of a multi-story building. Vibration time histories at non-instrumented floors of the building can be estimated from those recorded at the instrumented floors. It is shown by the Interferometric Imaging formulation that the top-to-bottom spectral ratio of the records of a particular story is dependent only on its properties of this story and those of its above neighboring ones. In other words, any change in the characteristics of the stories below does not affect the spectral ratio for the story under study. Therefore, starting from the top story, we can identify frequencies of each story, or directly the story's stiffness if its mass is known. Numerical examples using a simulated 10-story building confirm the validity of the approach.

\section{Acknowledgment}


The author is extremely thankful and sincerely acknowledges Prof. Erdal Safak, the chair of the Earthquake Engineering Department at Bogazici University, and Prof. Carlos Ventura at the University of British Columbia for their guidance, help, and many stimulating discussions.

\section{Reference}

Bernal, D., Ussia, A. 2015. Sequential deconvolution input reconstruction. Mech Syst Signal Process 50-51:41-55

Chang, P.C., Flatau A., and Liu S.C. 2003. Review paper: health monitoring of civil structure, Structural Health monitoring, v. 2(3) p. 257-67

Doebling, S.W., Farrar, C.R., Prime M.B., and Shevitz, D.W. 1996. Damage identification and health monitoring of structural and mechanical systems from changes in their vibration characteristics: a literature review, Report LA-13070-MS, Los Alamos National Laboratory, Los Alamos, NM

Derode, A., Larose, E., Campillo, M., and Fink, M. 2003. How to estimate the Green's function for a heterogeneous medium between two passive sensors? Application to acoustic waves, Appl. Phys. Lett. 83, 3054-3056.

Eftekhar, A.S., Chatzi, E., and Papadimitriou, C. 2015. A dual Kalman filter approach for state estimation via output-only acceleration measurements. Mechanical Systems Signal Processing 60-61:866-886

Erdik, M. 2001. Report on 1999 Kocaeli and Duzce (Turkey) Earthquakes, Proceedings of the 3rd International Workshop on Structural Control, Structural Control for Civil and Infrastructure Engineering, Casciati F., Magonette G., World Scientific. 
Fan, W. and Qiao, P. 2011. Vibration-based damage identification methods: a review and comparative study, Structural Health Monitoring, v. 10(1) p. 83-111

Hadjileontiadis, L.J. and Douka, E. 2007. Crack detection in plates using fractal dimension, Engineering Structures, v. 29, p. 1612-1625

Holzer, H. 1921. Die Berechung der Drehscwingungen, Springer-Verlag, Berlin, Germany

Iwan, W. D. 1997. Drift spectrum: measure if demand for earthquake ground motions, Journal of Structural Engineering, 123, 367-404.

Jaishi, B. and Ren, W., 2005, Structural Finite Element Model Updating Using Ambient Vibration Test Results. J. Struct. Eng., 10.1061/(ASCE)0733-9445(2005)131:4(617), $617-628$

Kaya, Y. and Dowling, J. 2016. Application of Timoshenko Beam Theory to the Estimation of Structural Response, Engineering Structures, (in press).

Kaya, Y., Kocakaplan, and S., Safak, E. 2015. System Identification and Model Calibration of Multi-Story Buildings through Estimation of Vibration Time Histories at Non-Instrumented Floors, Bulletin of Earthquake Engineering, v. 13, issue 11, p. 33013323

Kim J.T. and Stubbs N.. 2003. Crack detection in beam-type structures using frequency data, Journal of Sound and Vibration, v. 259, p. 145-160

Levin, R.I. and Lieven, N.A.J. 1998. Dynamic Finite Element Model Updating Using Annealing and Genetic Algorithms Simulated, Mechanical Systems and Signal Processing, v.12(1), p.91-121. 
Lobkis, O. I. and Weaver, R.L. 2001. On the emergence of the Green's function in the correlations of a diffuse field, J. Acoust. Soc. Am. 110, 3011-3017.

Naets, F., Croes, J., and Desmet, W. 2015a. An online coupled state/input/parameter estimation approach for structural dynamics. Comput Methods Appl Mech Eng 283:1167-1188

Naets, F., Cuadrado, J., Desmet, W., 2015b, Stable force identification in structural dynamics using Kalman filtering and dummy-measurements. Mech Syst Signal Process $50-51: 235-248$

Pandey, A.K., Biswas, M., and Samman, M.M. 1991. Damage detection from changes in curvature mode shapes, Journal of Sound and Vibration, v. 145, p. 321-332

Ratcliffe, C.P. 1997. Damage detection using a modified laplacian operator on mode shape data, Journal of Sound and Vibration, v. 204, p. 505-517

Rahmani, M., Ebrahimian, M., and Todorovska, M. 2015. Wave dispersion in high-rise Buildings due to Soil-Structure Interaction, Earthquake Engineering and Structural Dynamics, v. 44, issue 2, p. 317-232

Safak E. 1995. Detection and Identification of Soil-Structure Interaction in Buildings from Vibration Recordings, Journal of Structural Engineering, v. 121 p. 899-906

Safak, E. 1999. Wave-Propagation Formulation of Seismic Response of Multi-Story Buildings, Journal of Structural Engineering; 125:426-437

Snieder, R. 2004. Extracting the Green's function from the correlation of coda waves: a derivation based on stationary phase, Phys. Rev. E69, 046610 
Snieder, R. and Safak, E. 2006. Extracting Building Response Using Seismic Interforemtry: Therom and Application to the Milican Library in Pasadena, California, Bulletin of Seismological Society of America; vol.96 No:2 pp.586-598.

Stubbs, N., Kim, J.T., and Farrar, C.R. 1995. Field verification of a nondestructive damage localization and severity estimation algorithm, Proceedings of 13th International Modal Analysis Conference, v. 1, p. 210-218

Thomas, W.T. 2003. Theory of Vibration with applications: forth edition, Nelson Thornes Ltd., Cheltenham, UK, p. 387

Wapenaar, K., J. Thorbecke, and Dragonov, D. 2004. Relations between reflection and transmission responses of three-dimensional inhomogeneous media, Geophys. J. Int., v. 156, p. 179-194 
Table 1 Modal frequencies of the 10-story building with undamaged and damaged cases. The $20 \%$ decrease in the stiffness of the $9^{\text {th }}$ and the $6^{\text {th }}$ stories results in only $3.3 \%$ and $1.4 \%$ change in the $8^{\text {th }}$ and $1^{\text {st }}$ modal frequencies of the building, respectively.

\begin{tabular}{|c|c|c|c|}
\hline \multirow{2}{*}{$\begin{array}{c}\text { Mode } \\
\text { No }\end{array}$} & \multicolumn{3}{|c|}{ Modal frequency - (Change) } \\
\hline & Undamaged & Damaged (1) & Damaged (2) \\
\hline 1 & $0.71 \mathrm{~Hz}$. & $0.71 \mathrm{~Hz} .(0.3 \%)$ & $0.70 \mathrm{~Hz} .(1.4 \%)$ \\
\hline 2 & $2.11 \mathrm{~Hz}$ & $2.08 \mathrm{~Hz} .(1.5 \%)$ & $2.10 \mathrm{~Hz} .(2.8 \%)$ \\
\hline 3 & $3.47 \mathrm{~Hz}$. & $3.39 \mathrm{~Hz} .(2.3 \%)$ & $3.36 \mathrm{~Hz} .(3.2 \%)$ \\
\hline 4 & $4.75 \mathrm{~Hz}$. & $4.67 \mathrm{~Hz} .(1.6 \%)$ & $4.60 \mathrm{~Hz} .(3.1 \%)$ \\
\hline 5 & $5.92 \mathrm{~Hz}$. & $5.89 \mathrm{~Hz} .(0.4 \%)$ & $5.86 \mathrm{~Hz} .(0.9 \%)$ \\
\hline 6 & $6.97 \mathrm{~Hz}$. & $6.95 \mathrm{~Hz} .(0.1 \%)$ & $6.82 \mathrm{~Hz} .(2.0 \%)$ \\
\hline 7 & $7.84 \mathrm{~Hz}$. & $7.74 \mathrm{~Hz} .(2.1 \%)$ & $7.71 \mathrm{~Hz} .(1.7 \%)$ \\
\hline 8 & $8.55 \mathrm{~Hz}$. & $8.37 \mathrm{~Hz} .(2.1 \%)$ & 8.27 Hz. (3.3\%) \\
\hline 9 & $9.07 \mathrm{~Hz}$. & $8.95 \mathrm{~Hz} .(1.3 \%)$ & $8.89 \mathrm{~Hz} .(2.0 \%))$ \\
\hline 10 & $9.38 \mathrm{~Hz}$. & $9.35 \mathrm{~Hz} .(0.3 \%)$ & $9.22 \mathrm{~Hz} .(1.71 \%)$ \\
\hline
\end{tabular}


Table 2 Mass and stiffness distribution of 10-story shear-beam building. Damaged (1) and Damaged (2) show the stiffness distribution of the building at each story after the FE model of the building is calibrated at $9^{\text {th }}$ and $6^{\text {th }}$ stories, respectively. The final stiffness distribution of the building (i.e., Damaged (2)) can be used to detect the structural change (i.e., damage) in the structure.

\begin{tabular}{ccccc}
\hline \multirow{2}{*}{ Building } & Story Mass & \multicolumn{2}{c}{ Story Stiffness $\left(10^{\wedge}-2 \cdot \mathrm{kN} / \mathrm{m}\right)$} \\
Story & $\left(10^{\wedge}-6 \cdot\right.$ Ton $)$ & & \\
\cline { 2 - 4 } & & & & \\
\hline Story 1 & 5.625 & 0.5 & 0.5 & 0.5 \\
Story 2 & 5.625 & 0.5 & 0.5 & 0.5 \\
Story 3 & 5.625 & 0.5 & 0.5 & 0.5 \\
Story 4 & 5.625 & 0.5 & 0.5 & 0.5 \\
Story 5 & 5.625 & 0.5 & 0.5 & 0.5 \\
Story 6 & 5.625 & 0.5 & 0.5 & 0.5 \\
Story 7 & 5.625 & 0.5 & 0.5 \\
Story 8 & 5.625 & 0.5 & 0.5 & 0.5 \\
Story 9 & 5.625 & 0.5 & 0.5 & 0.5 \\
\hline
\end{tabular}


Fig. 1: A shear type multi-story building under base excitation of $\ddot{x}_{g}(\boldsymbol{t})$. The roofdeconvolved record of $\mathbf{T}_{\mathbf{n}}(\mathbf{z}, \boldsymbol{\omega})$ is only affected by the structural change (i.e., damage) at that story or stories above it. 
Fig 2 Two-Second segment of acceleration time histories of the Factor Building after being deconvolved by the roof acceleration record. Roof-deconvolved accelerations are color-coded based on their amplitudes. Neither the up-going waves nor the down-going wave shows any sign of reflection along the height of the building. 
Fig 3 Spectral ratios of each story of a 10-story building with (solid red line) and without (dashed blue line) damage. The damage is simulated at the $6^{\text {th }} \&$ the $9^{\text {th }}$ stories by reducing the stiffness of these stories by $20 \%$. The frequency shift at the $9^{\text {th }}$ story indicates damage at that story, but the similar frequency shifts at the stories below the $9^{\text {th }}$ story may not necessary indicate damage as they may stem from the structural change at upper stories 
Fig. 4 Spectral ratios of each story of a 10-story building: solid red line demonstrates the building with simulated damage at $9^{\text {th }} \& 6^{\text {th }}$ stories whereas the dashed blue line shows the building whose FE model is calibrated at $9^{\text {th }}$ story by reducing the story stiffness by $20 \%$. The frequency shift at the $6^{\text {th }}$ story again indicates damage, but the similar frequency shifts at the stories below the $6^{\text {th }}$ story may not necessary indicate damage 
Fig. 5 Spectral ratios of each story of a 10-story building: solid red line demonstrates the building with simulated damage at $9^{\text {th }} \& 6^{\text {th }}$ stories whereas the dashed blue line shows the building whose FE model is calibrated at $9^{\text {th }} \& 6^{\text {th }}$ stories by reducing the stiffness of these stories by $20 \%$. The perfect match between two models indicates that no further calibration on FE model of the building is necessary, and that the calibrated FE model already represents the final damaged state of the building 


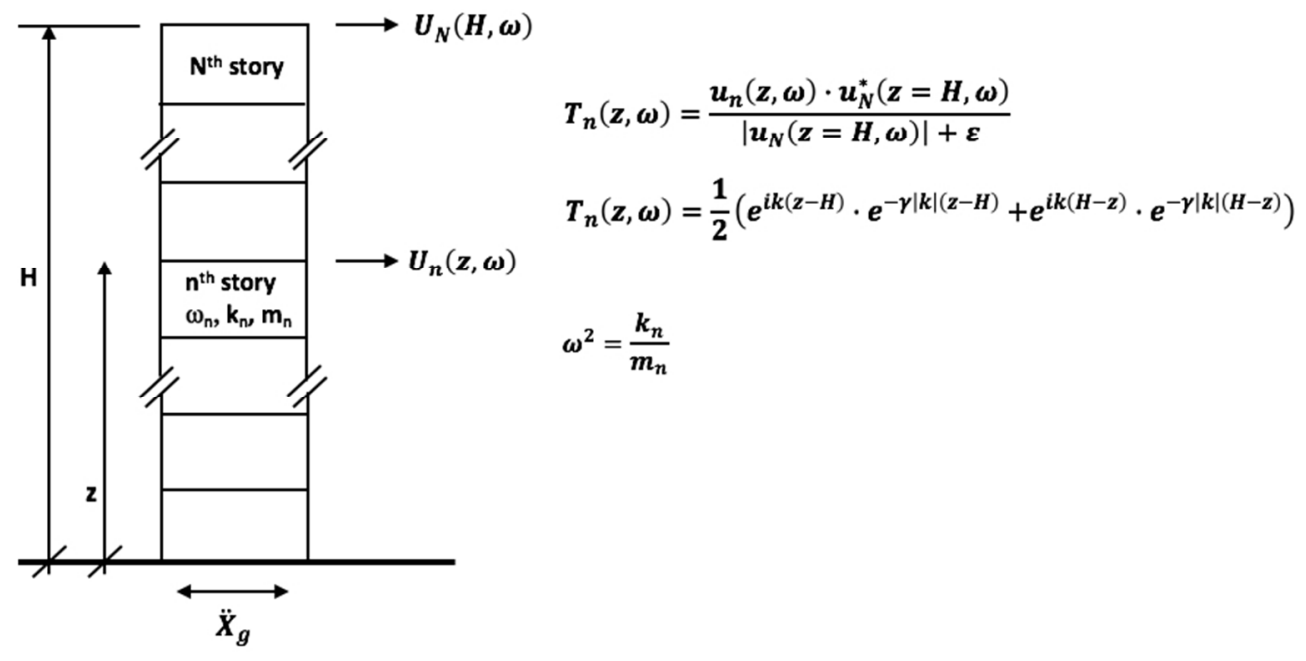
$313 \times 155 \mathrm{~mm}(72 \times 72 \mathrm{DPI})$ 


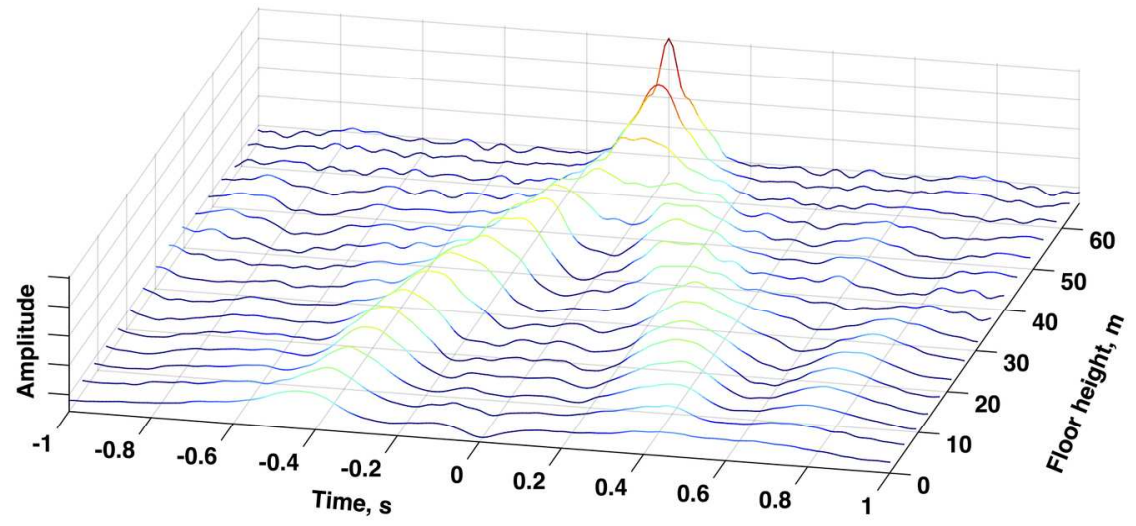

$173 \times 77 \mathrm{~mm}(300 \times 300 \mathrm{DPI})$ 

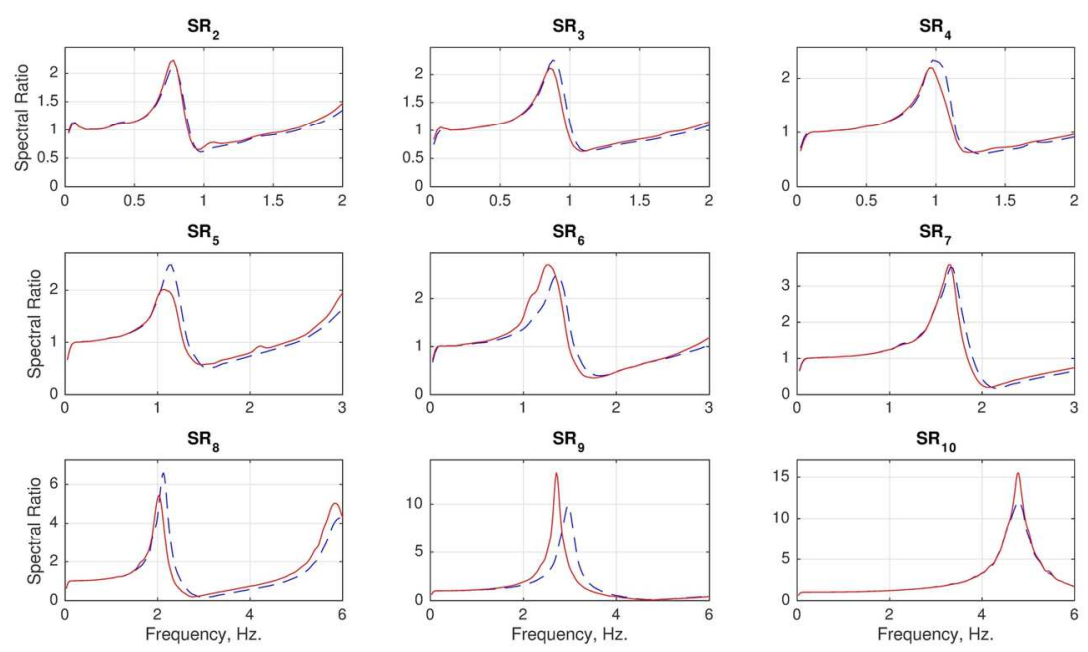

$155 \times 82 \mathrm{~mm}(300 \times 300 \mathrm{DPI})$ 

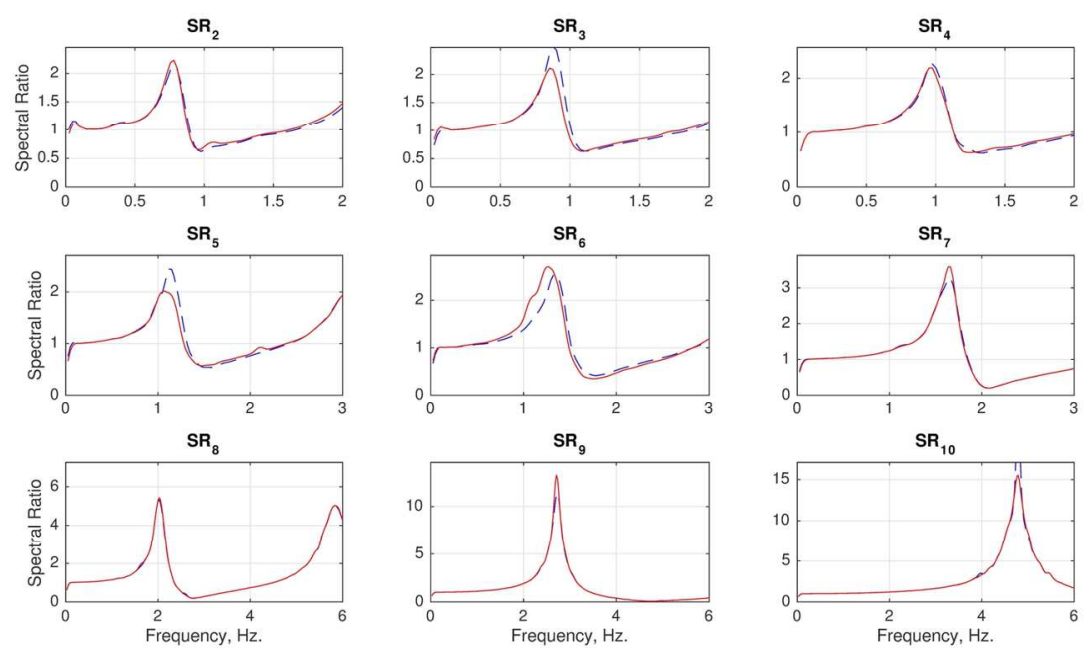

$155 \times 82 \mathrm{~mm}(300 \times 300 \mathrm{DPI})$ 

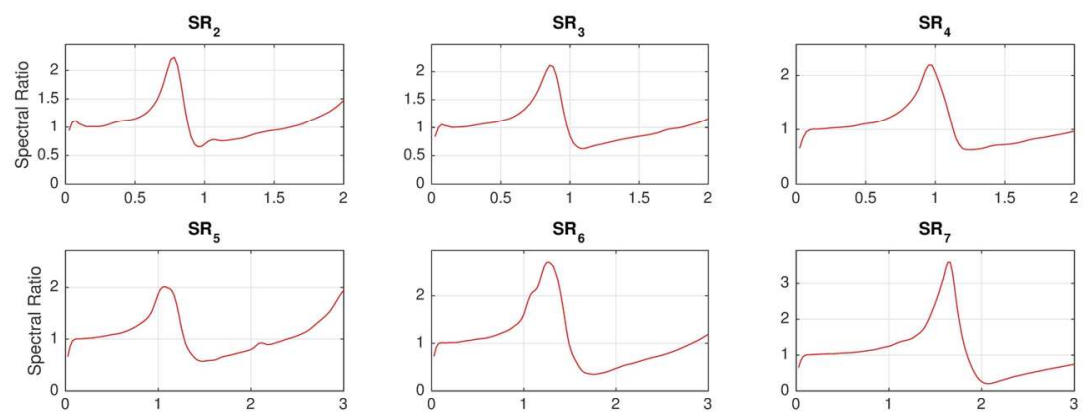

$\mathrm{SR}_{8}$

$\mathrm{SR}_{9}$
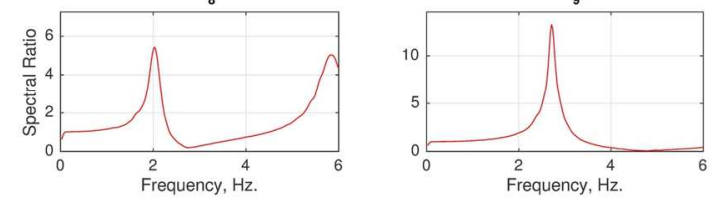

$\mathrm{SR}_{10}$

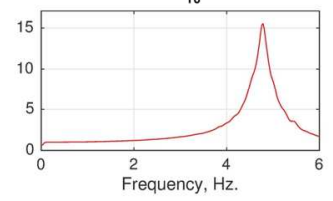

$154 \times 82 \mathrm{~mm}(300 \times 300 \mathrm{DPI})$ 